\title{
A CORPUS-BASED ANALYSIS OF THE COMPLEMENTATION PATTERNS OF THE ADJECTIVE "ASHAMED"
}

\section{Silviya Dimitrova1, Temenuzhka Seizova-Nankova ${ }^{2}$}

${ }^{1}$ Schule an der Mainstraße/Oberschule am Leibnizplatz, Bremen, Germany

${ }^{2}$ Faculty of Humanities, Konstantin Preslavsky University of Shumen, Shumen, Bulgaria

\begin{abstract}
The paper presents a corpus-based analysis of the predicative use of the adjective "ashamed" giving a full description of its complementation patterns with the help of the Valency Theory (VT-Herbst et al., 2004). The findings are based on a reference corpus extracted from the British National Corpus (BNC) by using the SkE software. The analysis reveals the advantages of the approach used for learners at levels B1 and B2 while, on the other hand, it shows the insufficiency of information found in the main English dictionaries (OALD, LDCE, etc.). It also demonstrates how both language learning and teaching, and materials production could be optimized using the corpus-based analysis.
\end{abstract}

Keywords: corpus analysis, predicative adjectives, ashamed, complementation patterns, dictionary entries, ELT

\begin{abstract}
About the author: Silviya Dimitrova holds an MA degree in Turcology from the University of Sofia and an MA degree in English Studies - Linguistics and Translation from Konstantin Preslavsky University of Shumen. Before embarking on her teaching career, she worked as a senior editor for the 'News in Turkish' programme of the Bulgarian National Television. From 2006 until 2009, she taught Gerenal English and EAP courses at METU NCC. In 2009, she moved to Germany where she taught both English and Turkish at the University of Oldenburg, Bremen University and Vechta University. Since 2017, she has primarily been working with illiterate refugee children at a state school in Bremen. Her interests are in the fields of CDA, migration, minority rights and multilingualism.
\end{abstract}

e-mail: halikarnas.s@gmail.com

ORCID iD: https://orcid.org/0000-0002-8633-2588

About the author: Associate Professor Temenuzhka Seizova-Nankova, PhD was born in Troyan. She received her MA at Sofia University in 1977. Temenuzhka Seizova-Nankova worked as a teacher of English in her hometown and in FL school in Lovech. Since 1990 she has been a lecturer at the English Studies Department, Shumen University. She has published in various frameworks: TGG, FG. Seizova-Nankova (2016) is based on CxnG approach to Argument Structure (Goldberg, Croft, Herbst). By analysing 6279 tokens of corpus drawn from BNC by SkE, a delicacy scale of item-specific to more generalized 'valency constructions' of V_hand(s) collocations is revealed. All her work is strongly motivated by foreign language linguistics.

e-mail: tseizova@yahoo.com; seizova@shu.bg

ORCID iD: https://orcid.org/0000-0002-4441-1624

\section{Copyright (C) 2021 Silviya Dimitrova, Temenuzhka Seizova-Nankova}

Article history: Received: 9 June 2020; Reviewed: 16 August 2021; Revised: 21 August 2021; Accepted: 21 August 2021; Published: 31 August 2021

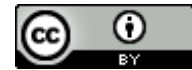

This open access article is published and distributed under a Creative Commons Attribution 4.0 International License.

Citation (APA): Dimitrova, S., \& Seizova-Nankova, T. (2021). A corpus-based analysis of the complementation patterns of the adjective "ashamed". Studies in Linguistics, Culture, and FLT, 9(2), 30-50. https://doi. org/10.46687/ZKKQ9762. 


\section{Introduction}

The advance of corpus linguistics in the past several decades has given researchers the opportunity to approach language analysis more thoroughly and systematically. Big English corpora like the British National Corpus (BNC) provide an extensive pool of naturally occurring utterances which, when analyzed and categorized, can shed more light onto how specific words are typically used. The new knowledge gained through such a corpus-based analysis has practical implications especially in the field of foreign and second language teaching and learning as it can reveal certain usage tendencies and preferences as well as give more detailed information about various combinatory possibilities which for lack of space are often absent from dictionary entries.

\section{Previous Research in the Field}

There are a number of corpus-based studies on adjective complementation published in the last decade, among which those of Doykova (2015), Doykova and Seizova-Nankova (2013), Doykova and Seizova-Nankova (2015), and Peneva (2015), among others.

In her PhD thesis, Doykova (2015) carries out a contrastive corpus-based analysis between English and Bulgarian on a great number of English adjectives and their complementation patterns (Herbst et al., 2004) with their Bulgarian functional equivalents. The analysis is based on a self-made English-Bulgarian translation corpus of English women fiction writers. As a whole, it is concluded that dictionaries only show typical usage of words but fail to give "a full account of the combinatorial aspect" which adjectives display and do not illustrate "the variety of prepositions accompanying them" (Mishan, 2005, cited in Doykova \& Seizova-Nankova, 2013, p. 49).

Peneva (2015), on the other hand, in her PhD thesis on the speech acts of apology describes the syntactic, lexico-semantic and pragmatic aspects of the predicative adjective "sorry" among others using the corpus-based approach by comparing a corpus of non-native speakers' utterances (of Bulgarian learners) to a reference corpus extracted from the BNC (the part of spoken language use which is $10 \%$ of the whole corpus). Basic patterns are identified and described by giving statistical information as to their relative frequency of use in both corpora on the basis of which conclusions are drawn.

\section{Methods and Methodology}

An important conception on which the current study is based is that "there are no hard and fast boundaries between lexis and grammar" (SeizovaNankova, 2016b, p. 21). The term lexicogrammar (Halliday, 1985) reveals the interdependency and inseparability of lexis and grammar, which according to 
Pearce (2007, p. 109) is evident everywhere in language. As Pearce points out, "the advent of corpus linguistics has made the identification of lexicogrammatical patterns much easier than it once was". Indeed, big corpora like the BNC can provide the language researcher with invaluable raw data on the basis of which interpretations can be made, conclusions drawn and new issues raised.

We follow practically the methodology in Seizova-Nankova (2016a, 2016b, 2019) concerning the usage-based and corpus-driven approach which relies strongly on corpus data ${ }^{1}$ in order to make conclusions in terms of description of structures using the lexical version of the Valency Theory (Herbst et al., 2004). The basic objective is to foreground the advantages of that approach especially for learners at B1 and B2 levels of English proficiency as compared to the lexicological approach even though learner dictionaries increasingly introduce new features relating to details of use based on big corpora using examples and exhibiting the combinability of lexical items. Of paramount importance is the use of a big and reliable corpus, in our case this is the 100-million-word BNC. A distinction is made between quantitative and qualitative corpus-based analysis of the syntactic structures (Herbst et al., 2004). The structures which the corpus data reveal illustrate the various patterns in which the adjective is found. In accordance with the VT, these patterns are analyzed in terms of their quantitative and their qualitative valency. The former (the quantitative valency) is related to the number of possible complements whereas the latter (the qualitative valency) is about the type of the complementation, e.g., a prepositional phrase (PP), a whclause ( $w h$-CL), a to-infinitive (to-INF), etc. As explained in Doykova (2015a, p. 18), "the valency approach highlights the enormous dimension of individual, word-specific knowledge that is part of a native speaker's competence and is one of the most systematic attempts to describe verbs, adjectives and nouns as valency carriers". It is this word-specific knowledge which seems to be inherent in native speakers' mental knowledge of the language that makes foreign and second language learning and teaching such a challenging task. It is also curious to know that "native speakers" (NSs) intuition (...) is not of help in making predictions about language use" (Seizova-Nankova, 2019, p. 4); therefore, the only way to gain insight into linguistic structures is by researching a big and reliable corpus.

\section{Lexicographical Approach}

According to the Online Etymology Dictionary, the word "ashamed" has a long history going back more than a thousand years. It existed in Old English as "asceamed", which was the past participle of the nowadays obsolete Old English verb "ascamian" (to feel shame). Today "ashamed" does not usually appear

\footnotetext{
1. The corpus drawn from the BNC on which the analysis is based is 58 pages long and for lack of space cannot be attached to the article as Appendix. Those who are interested, please, contact the authors.
} 
among the most commonly used English words and the two big dictionaries Cambridge Dictionary (CD) and Oxford Advanced Learner's Dictionary (OALD) only expect it from learners of English at the levels B1 and B2 respectively. LDCE, on the other hand, counts the word among the top 3,000 most frequent spoken words.

When we take a closer look at the dictionary definitions of the word "ashamed", we notice that most main dictionaries describe two separate meanings. Some dictionaries also give typical examples in which the word is used while others only choose to illustrate the meanings with examples without specifying the underlying usage patterns.

OALD defines "ashamed" as 1) "feeling shame or feeling embarrassed about somebody/something or because of something you have done" which appears in constructions like "ashamed of something", "ashamed of somebody", "ashamed of yourself"; "ashamed that..."; "ashamed to be something"; and 2) "unwilling to do something because of shame or fear of feeling embarrassed" which is realized in the form "ashamed to do something".

Longman Dictionary of Contemporary English (LDCE) takes a somewhat different perspective and identifies the two meanings of "ashamed" as 1) "feeling very sorry and embarrassed because of something you have done" which finds realization in the form of "ashamed oflat", "be ashamed to do something", "ashamed that", "belfeel ashamed of yourself"; and 2) "feeling uncomfortable because someone does something that embarrasses you" as in "ashamed of" and "ashamed to beldo something". Thus, the dictionary centers the meanings either around the speaker with his/her own doings leading to his/ her feeling ashamed or around third parties responsible for making the speaker feel ashamed. This approach differs from the one adopted by OALD which gives the different sources of "ashamed of" under one meaning but chooses to focus on the unwillingness to do something in a separate meaning.

CollinsD, on the other hand, has a solution to this seemingly inconsistent statement. It gives three meanings of the word "ashamed". Thus, both aspects, namely the source of the shame and the feelings of regret or reluctance are clearly illustrated: 1) "If someone is ashamed, they feel embarrassed or guilty because of something they do or they have done, or because of their appearance."; 2) "If you are ashamed of someone, you feel embarrassed to be connected with them, often because of their appearance or because you disapprove of something they have done."; 3) "If someone is ashamed to do something, they do not want to do it because they feel embarrassed about it." 


\section{Lexicogrammatical Approach}

"Ashamed" belongs to the class of adjectives expressing emotion. The standard case is that adjectives can be used either attributively, i.e., before a noun, or predicatively following link verbs such as "be", "feel", "become". In the case of the adjective "ashamed" dictionaries give the following information: CD adds [after verb], OALD and LDCE - [not before noun] and CollinsD - [verb-link adjective, adjective that]. Therefore, the word "ashamed" is an adjective typically used in a predicative position usually followed by certain complements.

The EVP (Erlangen Valency Patternbank), which offers patterns of verbs, adjectives and nouns based on VDE (Valency Dictionary of English), gives 15 patterns in total in which the adjective "ashamed" normally occurs. The same 15 patterns, grouped according to the prepositions they feature, are also described and illustrated with examples in the VDE. The attributive use of the adjective is included along with the different complementation patterns of the adjective in predicative position. In addition, the VDE gives the following explanation as to its meaning: "A person can be ashamed i) about, at, for or of a particular matter; ii) of, for or at a person or themselves, i.e., feel guilty for this reason".

In the BBI Combinatory Dictionary of English, the complementation patterns of the adjective "ashamed" have been described in three categories, namely prepositional phrases (about/of), the to-infinitive or a clause introduced by "that": 1. ashamed + about/of incl. ashamed + of_ReflPron + for_V-ing; 2. ashamed + to-INF and 3. ashamed + that_CL.

In Oxford Collocation Dictionary (OCD) along with the prepositions "about" and "of" the preposition "at" is included as well and the examples also present the pattern "ashamed + of_wh-CL". Thus, the only source which mentions the preposition "for" as a possible complementation of the adjective "ashamed" is the VDE together with the EVP, which is based on it.

\section{Description of the Corpus Data}

The reference corpus (RC) consists of 1036 concordance lines extracted from the BNC. i.e., all instances of the adjective "ashamed" found in the corpus. There are 5 utterances in which "ashamed" has been used attributively and 2 ungrammatical utterances which have not been taken into consideration in our analysis. The remaining 1029 utterances reveal 20 complementation patterns in total, in seventeen of which one of the prepositions "of", "at", "for", "about", "by" or "with" is involved. One and the same preposition can sometimes be complemented by various grammatical forms. Those variations are put together as subcategories of a single preposition. The reason for making this decision is that learners say e.g., "ashamed of" without paying further attention to the form of the complement to the preposition "of", which can vary to a considerable 
extent: [of_NP/_V-ing/_wh-CL/ReflPron+for_V-ing/ReflPron+in_V-ing]. These variations in the structure of the $\mathrm{PP}>[$ of_X] where $\mathrm{X}=\mathrm{NP} / \mathrm{V}$-ing/wh$\mathrm{CL} /$ ReflPron+for V-ing/ReflPron+in V-ing exhibit different frequency of use. Besides, it should be noted that sometimes, as can be the case in terms of context, the adjective has no need of a complement at all. This is called zero complementation and is marked [Ø]. Zero complementation is also meaningful as it is controlled by the immediate environment in which the adjective is used. In terms of frequency, the complementation patterns of the adjective "ashamed" are categorized and listed in a summarized form according to the preposition in the PP (where relevant) in Table $1^{2}$ and Table 2 below:

Table 1.

Frequency of use of the complementation patterns of the adjective "ashamed"a summarized presentation of complementation variations after prepositions

$\begin{array}{lll}\text { N Pattern } & \text { Number of utterances } & \text { Percentage rate } \\ 1 \text { [of_NP/_V-ing/_wh- } & 476 & 46,26 \% \\ \text { CL/ReflPron+for_V-ing/ } & & \\ \text { ReflPron+in_V-ing] } & & \\ 2 \text { [Ø] } & 297 & 28,86 \% \\ 3 \text { [to-INF/(of_ReflPron)_to-INF] } & 165 & 16,03 \% \\ 4[(\text { that }) \text { CL] } & 50 & 4,86 \% \\ 5 \text { [at_NP/_wh-CL/_V-ing] } & 17 & 1,65 \% \\ 6[\text { about_NP/_V-ing] } & 11 & 1,07 \% \\ 7 \text { [for_NP/_V-ing/wh-CL] } & 8 & 0,78 \% \\ 8[\text { by_NP] } & 3 & 0,29 \% \\ 9 \text { [with_NP/_wh-CL] } & 2 & 0,19 \%\end{array}$

Table 2.

Complementation patterns of the adjective "ashamed" - examples from the reference corpus

P1 [of_NP/_V-ing/_wh-CL/_ReflPron+for_V-ing/ReflPron+in_V-ing] (11) Ronni was instantly ashamed of her jealous feelings.

(152) Why should I be ashamed of writing to him?

(208) I'm not ashamed of what I do.

(407) Friends of Fonda's father said Peter should be ashamed of himself for linking a 'great name in movies' to such disgraceful junk.

(874) I HOPE the Attorney-General is ashamed of himself in allowing the sentence of rapist Dr Thomas Courtenay to stand.

2. Tab. 1 is a summary of the 20 complementation patterns of the adjective "ashamed" as follows: $1 / 5$ patterns, 2/1, 3/2, 4/1, 5/3, 6/2,7/3, 8/1, 9/2. 20 all in all. These patterns are all illustrated by examples in Tab. 2 . 
P2 [Ø]

(21) He was desperately ashamed!

P3 [to-INF/(of_ReflPron)_to-INF]

(114) I should be ashamed to stay where I wasn't wanted.

(949) When we stopped and slowly turned, with our bulging eyes in place, the gang scattered with such blood-curdling screams that we wondered if we hadn't overdone it, and felt sufficiently ashamed of ourselves never to use the eyes again.

P4 [(that $\left.) \_C L\right]$

(83) I am ashamed that I have abused their hospitality.

(449) 'I have me pride, James Halden, and I'm ashamed I ever let you come near me.'

P5 [at_NP/_wh-CL/_V-ing]

(180) The response was instantaneous, then she was ashamed at her reaction.

(880) 'I felt ashamed at what happened, 'she said.

(917) When, eventually he was able to take in his surroundings - the dingy room in a seedy lodging-house near Earls Court tube station - the became increasingly ashamed at having, as he felt, scarpered, even though Lisa had appeared not to want him to stay.

P6 [about_NP/_V-ing]

(607) He hadn't been ashamed about it.

(695) Golding's boys kept into themselves that they were ashamed about having enough courage to kill the pig.

P7 [for_NP/_V-ing/_wh-CL]

(367) In the first half, I began to be ashamed for ballet.

(484) I felt ashamed for having loathed my own life for so long.

(308) All the people of Sligo feel bitterly ashamed for what happened.

P8 [by_NP]

(766) Fergie's not ashamed by scandal photos, says mum.

P9 [with_NP/_wh-CL]

(689) Defence solicitor Seamus Hegarty, said O'Donnel was 'totally ashamed' with himself.

(960) ...they were going from tent to tent, from celebration to celebration having a great time and then the truth hit them they were ashamed with what they had done, they said to one another we are not doing right... 


\section{Basic Complementation Patterns of "ashamed" \\ [of_NP/_V-ing/_wh-CL/_ReflPron+for_V-ing/_ReflPron+in_V-ing]}

The complementation pattern featuring the preposition "of" is by far the most frequently used pattern in the RC. With its $46,26 \%$, it accounts for nearly half of all uses. It includes five subcategories, both simple and complex (Fig.1).

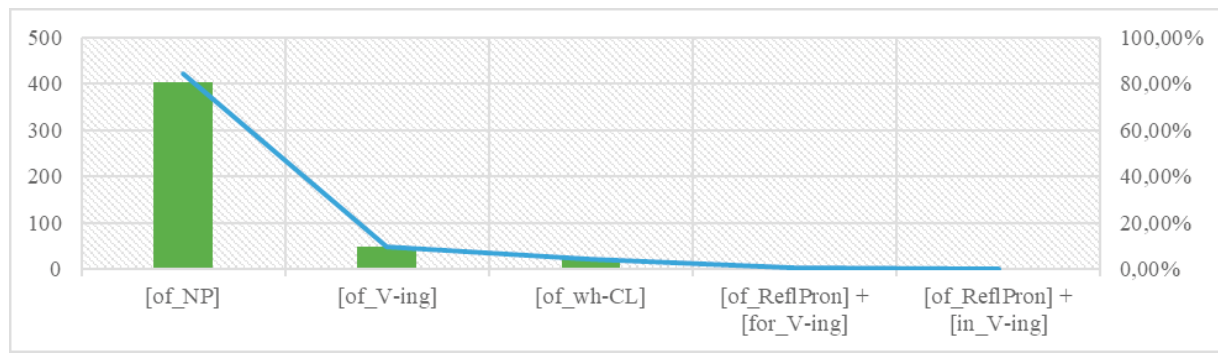

Figure 1. Frequency of use of the pattern variations of the complementation pattern with "of"

\section{[of_NP] complementation pattern}

The complementation pattern [ashamed] + [of_NP] appears 403 times, which makes it the most preferred pattern within the 476 concordance lines featuring the preposition "of". A possible explanation is that the pattern introduces both people and things one can be ashamed of. OALD illustrates this by listing "ashamed of something", "ashamed of somebody", "ashamed of yourself" before all other possible constructions (Tab.3).

Table 3.

Different uses of the complementation pattern [ashamed] + [of_NP] as given in OALD

$\begin{array}{lll}\text { [ashamed] + [of_NP] } & 403 \text { utterances } & 100 \% \\ \text { ashamed of something } & 259 & 64,27 \% \\ \text { ashamed of somebody } & 56 & 13,89 \% \\ \text { ashamed of oneself } & 88 & 21,84 \%\end{array}$

(165) We've been made to feel ashamed of our actions, of the past.

(56) He was constantly ashamed of his father, embarrassed by him, infuriated by him.

(150) He had asked her to marry him because he was ashamed of himself, because he wanted to hide. 
The reflexive pronoun requires special attention as it is featured in $21,84 \%$ of all utterances in this pattern with "myself" and "yourself" being the most frequently used pronouns, followed by "himself", "herself" and "themselves" (Tab.4).

Table 4.

Use of the reflexive pronouns in the pattern [ashamed] + [of_NP]

$\begin{array}{lll}\text { ashamed of oneself } & 88 \text { utterances } & 100 \% \\ \text { ashamed of myself/meself } & 19 & 21,59 \% \\ \text { ashamed of yourself } & 19 & 21,59 \% \\ \text { ashamed of himself } & 14 & 15,90 \% \\ \text { ashamed of herself } & 13 & 14,77 \% \\ \text { ashamed of itself } & 5 & 5,68 \% \\ \text { ashamed of ourselves } & 2 & 2,27 \% \\ \text { ashamed of yourselves } & 2 & 2,27 \% \\ \text { ashamed of themselves/theirselves } & 14 & 15,90 \%\end{array}$

What can also be observed here is the use of the pattern [ashamed] + [of_NP] with a changed word order placing the NP before the adjective. This is an emphatic structure which Halliday (1985) describes as a grammatical metaphor (Seizova-Nankova, 2016a, pp. 57, 67, 85, 145, 221, 246, 295, which is different from structural and lexical metaphor, pp. 295-296). The reason for being or feeling ashamed is represented by the NP, normally expressed with one of the indefinite pronouns "nothing", "something" or "anything" combined with the passive infinitive of the verb "be" in postmodification.

(185) My group has nothing to be ashamed of, but, like everybody else nowadays, we suffer from a general shortage of cash.

As already shown, reflexive pronouns account for every fifth use of the complementation with "of". In some cases, information is also given as to why somebody feels or should feel ashamed of oneself.

(448) Sarah's eyes flooded with tears, and she was ashamed of herself for not being more charitable over this generous woman's good fortune.

\section{[of_V-ing] complementation pattern}

We encounter this pattern 47 times in the 1029 concordance lines, on which this investigation is based. Within the utterances featuring the preposition "of", it is responsible for $9,87 \%$ of the uses. In other words, almost every tenth utterance contains a complement with $\mathrm{V}$-ing. Its use and meaning are not different from 
those of the pattern [ashamed] + [of_NP] as the gerund (V-ing) functions as a noun:

(120) He was very red in the face, probably because he was ashamed of using that horrible word, Oliver thought.

(170) 'That's right' they said, 'don't be ashamed of giving way to your emotions.'

\section{[of_wh-CL] complementation pattern}

This is another variation of the main pattern with "of" where the NP is substituted by a $w h$-clause. It accounts for $4,41 \%$ of all utterances in the category, look at the following examples:

(491) But being ashamed of who they are, they're making it harder for other people to accept them.

(842) We may be ashamed of what we've said or done.

\section{[of_ReflPron] + [for_V-ing] complementation pattern}

This complex pattern is a variation of [of_NP] where the NP is represented by a reflexive pronoun. As we have already shown, reflexive pronouns account for every fifth use of the complementation with "of". In rare cases, information is also given as to why somebody feels or should feel ashamed of oneself. This information is introduced by the preposition "for" followed by a V-ing form:

(138) If he is beginning to share the public anxiety about standards in our schools, he should be ashamed of himself for having resisted each and every reform that has been aimed at reversing the trend and improving them.

(448) Sarah's eyes flooded with tears, and she was ashamed of herself for not being more charitable over this generous woman's good fortune.

\section{[of_ReflPron] + [in_V-ing] complementation pattern}

This pattern appears in one single utterance. We believe that in order to prove its validity, more research using other big corpora such as COCA should be done.

(874) I HOPE the Attorney-General is ashamed of himself in allowing the sentence of rapist Dr Thomas Courtenay to stand.

\section{[to-INF/(of_RefIPron)_to-INF]}

The pattern appears 165 times in the RC. This constitutes $16,03 \%$ of all utterances. The simple infinitive is by far the most frequently used one with 143 instances in total ( $>$ Table 5). There are generally no more and no less than 6 infinitive forms to be identified. These are: i) the simple (to write), ii) the passive (to be written), 
iii) the perfect (to have written), iv) the perfect passive infinitive (to have been written), v) the progressive (to be writing), vi) the perfect progressive (to have been writing). All these forms are marked [to-INF]. Of these, four (4) forms are found and identified in the corpus. Table 5 is an illustration of the varieties of the infinitive complementation pattern, hence a great variety of meanings.

Table 5.

Different infinitive forms in the to-INF pattern

$\begin{array}{llll}\text { [to-INF] pattern } & & 165 \text { utterances } & 100 \% \\ \text { 1.[to-INF] } & \text { simple } & 143 & 86,67 \% \\ \text { 2.[to-INF] [to be+V-ed] } & \text { passive } & 13 & 7,88 \% \\ \text { 3.[to-INF] [to have+V-ed] } & \text { perfect } & 7 & 4,24 \% \\ \text { 4.[to-INF] [be+V-ing] } & \text { progressive } & 2 & 1,21 \%\end{array}$

OALD states that the pattern [ashamed] + [to-INF] appears in the first meaning, namely "feeling shame or feeling embarrassed about somebody/something or because of something you have done" when the [to-INF] is expressed by the verb "be" as in "ashamed + to be something". When other verbs are used in this structure, the meaning is the second one, namely "unwilling to do something because of shame or fear of feeling embarrassed" as in "ashamed + to do something".

Such a distinction cannot be made in the definition given by LDCE. According to this dictionary, we can use the structure "be ashamed to do something" for both: "feeling very sorry and embarrassed because of something you have done" and "feeling uncomfortable because someone does something that embarrasses you". In the second case, "be ashamed to be something" can also be used. We find this explanation problematic for two reasons. First, the dictionary fails to identify shame as an anticipated emotion resulting from an action still to be taken or being taken at the moment of speech and only focuses on past actions. Second, it is not clear how the structure "ashamed to be/do something" can be used when third parties are the source of someone's embarrassment.

If we follow the distinction offered by OALD, we can group the 165 corpus examples into a smaller group of 16 utterances featuring the infinitive of the verb "be" and a bigger one consisting of the remaining 149 utterances. The utterances in which the adjective "ashamed" is complemented by the infinitive of the verb "be" fit the definition given by OALD and represent current states:

(25) Yes, well, there are times when I'm ashamed to be human if that's what it means.

(555) 'You are not ashamed to be the guest of a traitor of his country?' 
As for the remaining 149 utterances, they don't present such a clear-cut picture because the meaning "unwilling to do something" cannot be applied to all. In the utterance (69) "In those days captains of industry were not ashamed to live close to the source of their wealth." living close to the source of wealth is not something captains of industry are (not) unwilling/reluctant to do for they already live there. Therefore, this use of the infinitive fits the meaning "If someone is ashamed, they feel embarrassed or guilty because of something they do or they have done" as found in CollinsD.

There is a similar situation when the progressive/continuous or perfect forms of the infinitives are used. In such utterances there is a clear reference to a time point earlier than the speech moment, i.e., the feeling of shame is a result of something which has already been done/has happened, or the emphasis is on an action in progress, at the moment of speech, respectively.

(47) It's not a statement, it is a waste of paper and you should be ashamed to have bought it.

(37) I was half proud, half ashamed to be using it in this way.

Utterances like (47) and (37) are clearly different in meaning from utterances like (20) and (18)

(20) I'm ashamed to say I've never eaten Greek food before.

(18) I'm almost ashamed to admit it, but I'm still something of a beginner.

In the latter two, the act of saying or admitting something at the moment of speech is the anticipated source of shame or embarrassment - the case identified in OALD as the second and in Collins Dictionary as the third meaning of the adjective "ashamed". Therefore, both the form and the meaning of the infinitive play an important role when interpreting the pattern [ashamed] + [to-INF]. In 13 utterances with the simple form of the infinitive the meaning is "If someone is ashamed, they feel embarrassed or guilty because of something they do or they have done". Most infinitives here are verbs like "have" ( $>$ eg.75), "own", "believe", "hear", "remember" and "think", or verbs like "live".

\section{(75) 'Captain Mitford made me ashamed to have English blood.}

If we take out the 13 utterances which in our opinion cannot be interpreted as "reluctancy to do something" we have 114 remaining utterances with a simple infinitive and in 58 of them the infinitive is a verb of communication, e.g., "tell”, "say” (eg.55), "admit” (eg.115), "announce”, "cry”, "mention”, "confess", "put down in words", "speak out”, "inquire”, "report”.

(55) No, I'm ashamed to say it but the only time I've seen Leeds away was the charity shield at Wembley.

(115) She felt totally unnerved by the encounter, and wasn't ashamed to admit it. 
As for the rest of the verbs used in this way, we notice that they often represent acts of showing, revealing, facing and finding something, appearing or staying somewhere, i.e. action verbs like "bring", "meet", "play", "come", "use", "take" and "make".

(26) Then she looked away, as if ashamed to show her feelings.

(281) I'd be ashamed to bring my boss here or any influential person from work.

(360) Was he ashamed to meet men to whom he talked two ways?...

\section{[(that)_CL]}

The pattern with the conjunction "that" introducing a finite clause accounts for only $4,86 \%$ of the uses of the adjective "ashamed". It is found 50 times in the reference corpus and even though the use of the conjunction is optional, in this case "that" is almost always used. It is found in 45 out of 50 sentences. The structure and the occurrences with "that" followed by a finite clause are straightforward and introduce the explanation and/or clarification why somebody feels or should feel "ashamed". This use corresponds to OALD and LDCE's first meaning of the adjective, namely "feeling very sorry and embarrassed because of something you have done", where the use "ashamed that" is explicitly given. Yet, when one carefully reads the dictionary definitions, one begins to feel doubt whether they mean this construction is used only when the subject of both the main and the subordinate clause is one and the same personal referent. A closer examination of the examples from the BNC shows that in most sentences this is indeed the case but the use is nevertheless not limited to it:

(64) She felt ashamed that she had left him and made her own escape.

(129) Is he not ashamed that so many children have been thrown on to the streets of Scotland while he has been Primer Minister?

(449) 'I have me pride, James Halden, and I'm ashamed I ever let you come near me.'

Among the 50 sentences in this complementation pattern there are five in which there is a special emphasis achieved by using "so" in front of the adjective.

(405) Mr Alan Williams, prosecuting, told the jury the girl was so ashamed she did not tell her parents until April and a 'hurried termination' was arranged.

(841) When I pressed them to imagine the result of such an event, they replied the murderer would be so ashamed (lidya) that she/he would leave the region altogether never to return; again withdrawal. 


\section{Complementation patterns with other prepositions}

The prepositions "at", "about", "for", "by" and "with", especially when compared to the preposition "of", can be described as very rare because they appear in only $3,98 \%$ of the utterances featuring "ashamed".

\section{[at_NP/_wh-CL/_V-ing]}

The pattern is not often used and represents only 1,65\% of all occurrences featuring the adjective "ashamed". Most dictionaries don't even mention this option, thus excluding the preposition "at" as a possible complementation with the adjective "ashamed". The only dictionary where the preposition is found is the LDCE where "at" is given as an alternative to "of": "ashamed of/at" in the meaning "feeling very sorry and embarrassed because of something you have done". A closer examination of the 17 utterances in which this pattern is found suggests that although the preposition "at" can be substituted by "of", there is an element of unexpectedness, of suddenly being faced with a situation that provokes feelings of shame. Explaining the prepositional phrase complements of adjectives Downing (2015, pp. 439-440) states that whereas the preposition "of" indicates "mental state in terms of the antagonist or process", the preposition "at" focuses on the "emotional reaction to something or someone". In any case, more research should be conducted and the use of these two prepositions in combination with the adjective "ashamed" better clarified.

(180) The response was instantaneous, then she was ashamed at her reaction.

(880) 'I felt ashamed at what happened,' she said.

(917) When, eventually he was able to take in his surroundings - the dingy room in a seedy lodging-house near Earls Court tube station - he became increasingly ashamed at having, as he felt, scarpered, even though Liza had appeared not to want him to stay.

\section{[about_NP/_V-ing]}

The pattern is quite rare. It appears 11 times in total in the $\mathrm{RC}$, which constitutes $1,07 \%$ of all utterances featuring "ashamed". None of the main English dictionaries we have consulted suggests it as a possible complementation of the adjective. It is found only once in an example offered by LDCE but not in the section where the meanings of the word are explained and clarified. It is in a section further down called "Examples from the Corpus". We find this confusing for the learner because earlier on, in the section "Grammar: Comparison" the dictionary demonstrates the different patterns of use of the synonyms "ashamed" and "embarrassed". One is left to believe that while "ashamed" is used with the preposition "of" when referring to both people and things, in the case of 
"embarrassed" the preposition is "by" when referring to people and "about" when referring to things.

The preposition "about" can only be found in specialized dictionaries focusing in particular on complementation patterns. It is featured in the VDE together with "at", "for" and "of" when the shame one feels is related to a particular matter. It appears in the BBI Combinatory Dictionary of English as an alternative of "of" without specification about the particular uses. The preposition "about" is also mentioned along with "of" and "at" in the OCD again without mentioning potential differences of meaning.

This information gives us reason to believe that the preposition "about" does only introduce inanimate sources of shame. It is, however, not enough to provide a clear explanation as to when to use "of" and when "about". We can interpret the meaning implied by "about" as "feeling shame in relation to something" and understand "ashamed of" as "ashamed because of" but we believe this matter should be further researched.

(796) Americans get so ashamed about that kind of attitude.

(935) People had begun to feel less ashamed about being greedy and of wanting more than their share of fairness.

\section{[for_NP/_V-ing/_wh-CL]}

The pattern is found in only $0,78 \%$ of the utterances featuring "ashamed". It can be said that it is hardly ever used. A close examination of the information about the adjective provided by the main English dictionaries confirms this. Only the Merriam-Webster Dictionary (MWD) gives one single example featuring this preposition together with 3 examples with "of" under the meaning "feeling shame, guilt or disgrace". The insufficiency of the provided information can be misleading as in all three examples "of" introduces a NP whereas "for" is used together with a V-ing form. Based on these examples one might conclude that there is a change of preposition when V-ing is used. However, this investigation has already shown that [of_V-ing] is a much more preferred structure with $4,57 \%$ of all occurrences.

(It was strange seeing nuns outside.) (372) I felt ashamed for them.

(484) I felt ashamed for having loathed my own life for so long.

(308) All the people of Sligo feel bitterly ashamed for what happened.

\section{[by_NP]}

The pattern is represented by only 3 utterances in the RC. The preposition "by" serves to indicate the source of shame expressed by the person who experiences it. All dictionaries we have referred to suggest the preposition "of" in this 
meaning. The use of the preposition "by" as seen in these utterances can be related to an analogy the producer of the utterance has made with collocations like "amazed by", "shocked by", "disturbed by", "excited by", "impressed by" because in all these it is the preposition "by" that introduces the source of the emotion in question.

(625) For many of us the practice was sternly discouraged in our childhood and, without doubt, many of us still feel embarrassed or ashamed by our own "indulgence".

\section{[with_NP/_wh-CL]}

The two variations of the pattern appear once each and we believe that this use is rather accidental, probably again based on analogy with other adjectives which collocate with "with" such as "annoyed with", "bored with", "angry with". The preposition "of" is the preferred/correct alternative found both in the big English dictionaries and in the BNC.

(689) Defence solicitor Seamus Hegarty, said O'Donnell was 'totally ashamed' with himself.

(960) ...that festival to this special meeting to that one, I'm gonna have my good time well that was what these fella's were doing, they were going from tent to tent, from celebration to celebration having a great time and then the truth hit them they were ashamed with what they had done, they said to one another we are not doing right, this days a day of good news, but we are keeping silent, if we wait until morning light punishment will overtake us, now therefore, come, let us go...

\section{Findings and Discussion}

The results of the investigation can be summarized in a three-fold manner:

1. Complementation patterns

The research is an in-depth description of the complementation patterns of "ashamed", thus confirming 100\% the patterns included in VDE and adding more alternative complementations. This means two things: i) as not all adjectives are included in the dictionary (cannot possibly be done), the fact that "ashamed" is, speaks for itself about its importance for the study and for the acquisition of the English language, ii) besides, the BNC corpus (Kilgariff et al., 2004) proves to be a good representative of English and hence, its name Reference corpus, i.e., teachers can be encouraged to use it in order to give their students an adequate exposure to "good examples". What is more, the relative frequency of the patterns listed above gives a fair picture of what the preferred and less preferred options of use are (>Tab. 1,2). Only some of them are described in the main English dictionaries. 
Having limited space, the main English dictionaries possibly include only the most frequent uses of "ashamed", which may lead to a complete absence of patterns with prepositions used by native speakers. Examples in dictionaries can even be misleading because for the sake of brevity they use different complementation patterns with different prepositions and this can give the inexperienced language learner the idea that certain prepositions are used with certain complements. What is actually the case is that one and the same preposition can often be part of alternative complementation patterns.

The reflexive pronouns used with "ashamed", which according to the data from the BNC are frequently used, are mentioned only briefly in most big dictionaries and especially the complex complementation [of_ReflPron] + [for_V-ing] is hardly ever present. Of the five big English dictionaries we have consulted, only two, namely CD and OALD, illustrate the structure with a single example utterance each (> Tab. 3, 4).

As already shown above, the use of the [to-INF] pattern presents difficulties in terms of interpreting the meaning of the utterance or in choosing the right pattern with certain verbs. Here again, the main English dictionaries do not provide sufficient support to non-native speakers of English and only a corpusbased study like the present one can shed more light into this problem.

\section{Linking verbs}

The $\mathrm{RC}$ also reveals that by far the most frequent linking verb used with the adjective is "be" but it is not the only one. This brings diversity and also shows nuances of meaning. 11 linking verbs have been revealed in the corpus, with "be" and "feel" being the most frequently used ones.

\section{Adjective modification}

Based on the RC from the BNC, we have counted 45 adverbs of degree and manner which are present in 19,24\% of all utterances. Such information is given by the big dictionaries only sporadically and in most cases needs to be extracted from the example utterances. Only LDCE explicitly mentions link verbs and adverbs in the following structures: "be/feel ashamed of yourself" and "deeply/ bitterly/thoroughly ashamed".

\section{Implications for ELT}

The findings shown above give additional innovative aspects to the analysis of adjectives. The results also give good foundation for raising hypotheses for ELT. Hypothesis 1: as some adjectives are usually translated in Bulgarian by a verb (see https://eurodict.com/dictionary/ashamed-3918, срамувам се, срам ме e $\mathrm{oT}^{3}$ ), it can be hypothesized that Bulgarian users of English especially at A2

3. The Latin transcription of the Bulgarian verbs: sramuvam se, sram me e ot 
and B1 level will substitute the Bulgarian preposition "оt" (от) with the English one "from". Hypothesis 2: the diversity of linking verbs in students" production data would most probably be limited to "be" and/or "feel", and Hypothesis 3 : the same is the case with the modification of adjectives in English by Bulgarian learners as compared to the English corpus data. All these hypotheses can be considered further for future studies.

The results of corpus-based studies like the current one can help materials designers and foreign language teachers to make the right choices when teaching certain words and structures. In the case of the adjective "ashamed", we have revealed that the main focus should be on the pattern variations with the preposition "of" because these are by far the most frequently used structures. Special attention here should be paid to the use of the reflexive pronouns and the extra slot they open within the complementation, and appropriate practice should be provided to students. With more advanced students the other possible prepositions should be discussed as well but their limited use should be explicitly stated and the focus should be on synonymous structures and special nuances of meaning.

Another problematic area worth spending time on in the classroom is the use of the to-INF complementation. By discussing various corpus examples and comparing them with utterances in which the V-ing complementation has been used, students can get a better understanding for the appropriate choice of verbs in the to-INF pattern.

The RC used in this study can also serve to provide material for extensive practice in modifying the adjective with different adverbs. The astonishing variety we have witnessed here is relevant for learners as it is a way to achieve variety and richness of expression.

All in all, ELT can only benefit from corpus-based analyses like the one described here as these provide important insights into what is common in language and are a rich source of ideas for materials production and teaching in the foreign language classroom.

\section{Conclusions}

The lexicogrammatical description of the adjective "ashamed" which was object of investigation by means of the usage-based approach is an efficient way of gaining detailed information about the adjective "ashamed" in terms of its complementation patterns, linking verbs and adjective modification. The results have been clearly manifested by means of 5 tables and one figure for greater visibility of the knowledge achieved by the research. Such information is difficult to come by by simply reading or checking the dictionaries but can most adequately be used by teachers in whatever way they find suitable for their purposes. 


\section{References:}

Benson, M., Benson, E., \& Ilson, R. (2009). The BBI Combinatory Dictionary of English: Your guide to collocations and grammar. Amsterdam: John Benjamins.

BNC (n.d.). British National Corpus. http://www.natcorp.ox.ac.uk/

Downing, A. (2015). English Grammar: A University Course. $3^{\text {rd }}$ edition. New York: Routledge.

Doykova, I. (2015a). Adjective Complementation with BE in English and its Bulgarian Translation Equivalents. PhD Thesis. Shumen: Konstantin Preslavsky University Press.

Doykova, I. (2015b). Adektivnata komplementaciya s BE v angliyskiya ezik $i$ bylgarskite i prevodni ekvivalenti. PhD Thesis. Abstract. Shumen: Konstantin Preslavsky University Press.

Doykova, I., \& Seizova-Nankova, T. (2013). Predicative Adjectives in ESP - a Corpus-Based Methodology. In Nedelcheva, S. \& Cheshmedzhieva, D. (Eds.). Dynamics, Interdisciplinarity, Diversity. (pp. 43-52). Shumen: Konstantin Preslavsky University Press.

Doykova, I., \& Seizova-Nankova, T. (2015). Identification of the Category of Adjective in English. A Corpus-Based Approach. In Cheshmedzhieva, D. (Ed.). The Global and the Local. Modern Trends in English Studies and Translation. (pp. 38-49). Shumen: Konstantin Preslavsky University Press.

Erlangen Valency Patternbank. Retrieved from: http://www.patternbank.unierlangen.de/cgi-bin/patternbank.cgi

Halliday, M.A.K. (1985). An Introduction to Functional Grammar. $1^{\text {st }}$ edition. London: Edward Arnold.

Herbst, T., David, H., Roe, I., \& Götz, D. (2004). A Valency Dictionary of English. A Corpus-Based Analysis of the Complementation Patterns of English Verbs, Nouns and Adjectives. Berlin: Mouton de Gruyter.

Kilgariff, A., Rychly, P., Smrz, P., \& Tugwell, D. (2004). The Sketch Engine. In: Proceedings of the XI EURALEX International Congress. (pp.105-116). Lorient: Universite de Bretagne-Sud. Reprinted in: Hanks, P. (ed.). Lexicology: Critical Concepts in Lingistics. London: Routledge.

Pearce, M. (2007). The Routledge Dictionary of English Language Studies. New York: Routledge.

Peneva, D. (2013). Quantitative and Qualitative Analysis of the Apology Speech Act "Sorry". In Nedelcheva, S., \& Cheshmedzhieva, D. (Eds.). Dynamics, Interdisciplinarity, Diversity. (pp. 29-42). Shumen: Konstantin Preslavsky University Press. 
Peneva, D. (2015). Recheviyat akt izvinenie v produkciyata na bylgari, ucheshti angliyski ezik. PhD Thesis. Abstract. Shumen: Konstantin Preslavsky University Press.

Seizova-Nankova, T. (2016a). Lexicogrammar of $V$ hand(s) collocations. A corpus-driven analysis. Shumen: Konstantin Preslavsky University Press.

Seizova-Nankova, T. (2016b). Valency Constructions at Work: A Case Study. In Todorova, R., et al (Eds.). Challenges in English Teaching and Research. Studies in Linguistics, Culture and FLT, Vol. 1. Shumen: Assenevtsi Publishing House, 21-41.

Seizova-Nankova, T. (2019). Innovative Methods in Learning Business English for Tourist Students. A Case Study. In Mileva, S., \& Popova, N. (Eds). Research, Development and Education in Tourism. (pp. 241-292). Cambridge Scholars Publishing. 


\section{Dictionaries}

CD. Cambridge Dictionary. https://dictionary.cambridge.org/

https://dictionary.cambridge.org/dictionary/english/ashamed. Accessed 24 July 2020.

CollinsD. Collins Dictionary. https://www.collinsdictionary.com/dictionary/ english

https://www.collinsdictionary.com/dictionary/english/ashamed. Accessed 24 July 2020.

LDCE. Longman Dictionary of Contemporary English. https://www.ldoceonline.com

https://www.ldoceonline.com/dictionary/ashamed. Accessed 24 July 2020.

MWD. Merriam-Webster online dictionary. https://www.merriam-webster.com https://www.merriam-webster.com/dictionary/ashamed\#learn-more. Accessed 24 July 2020.

OALD. Oxford Advanced Learner's Dictionary. https://www.oxfordlearnersdictionaries.com/

https://oxfordlearnersdictionaries.com/definition/english/ashamed?q=ashamed. Accessed 24 July 2020.

OCD. Oxford Collocation Dictionary. (2002). Oxford: Oxford University Press.

OED. Online Etymology Dictionary. https://www.etymonline.com/ https:// www.etymonline.com/word/ashamed. Accessed 24 July 2020. 